\title{
PHYSICAL ACTIVITY AND SELF-ESTEEM IN ADULTS WITH JUVENILE IDIOPATHIC ARTHRITIS
}

\author{
Rodrigo Joel de Oliveira ${ }^{1}$, Paulo Rogério Julio ${ }^{1}$, Paula Fernandes ${ }^{1}$, Roberto Marini ${ }^{1}$, Simone Appenzeller ${ }^{1, \star}$ \\ 1.Universidade Estadual de Campinas, Campinas (SP), Brazil. \\ *Corresponding author: appenzellersimone@gmail.com
}

\section{BACKGROUND}

With improvement of treatment, long-term factors influencing quality of life have to be addressed in the care of juvenile idiopathic arthritis (JIA) patients. The aim of our study was to compare body composition, level of physical activity and self-esteem of adult patients with JIA.

\section{METHODS}

The levels of physical activity were analyzed using the International physical activity questionnaire (IPAQ) short version. The body composition data were collected using the Omron HBF 514 C vertical electric bioimpedance device. The Rosenberg self-esteem scale was used to assess positive and negative attitude and feelings about themselves, where the lower the score, the higher the individual's self-esteem. For the statistical analysis of the data, the IBM SPSS software was used with a significance index of $p<0.05$.

\section{RESULTS}

We included 81 individuals > 18 years, 38 with $J A$ and 43 healthy people (control group, CG). The female sex was the largest participant in this research. There was no significant difference regarding sex (female $=28$ [73.7\%] in JIA and 26 [60.5\%] in CG) and age of the groups $(29.39 \pm 7.6$ vs. $31.1 \pm 3.1, p=0.18)$. The $C G$ showed greater height and body weight $(163.5 \pm 9.8 \mathrm{vs} .169 .6 \pm 8.0$, $p<0.001 ; 63.07 \pm 16.65$ vs. $69.33 \pm 6.88, p=0.003$, respectively), but no difference in the body mass index (BMI) was observed $(24.32 \pm 4.9$ vs. $24.12 \pm 2.09, p=0.8)$. The JIA group had a higher percentage of total fat mass $(31.65 \pm 10.20 \mathrm{vS} .28 .47 \pm 4.9, p=$ 0.07), while the CG had a higher percentage of total muscle mass $(29.7 \pm 6.5 \mathrm{vs} .35 .86 \pm 6.05, p<0.001)$. The self-esteem of JIA patients was lower than in the CG ( $21 \pm 3.9$ vs. $16.26 \pm 4.3, p<0.001)$. In the IPAQ classifications, JIA patients were classified as less physically active than the CG (2.63\% vs. $20.93 \%, p=0.022)$, less irregularly active ( $5.26 \%$ vs. $23.25, p=0.023)$ and a higher level of sedentary lifestyle (65.78\% vs. $25.58 \%, p<0.001)$. A higher percentage of muscle mass was associated with greater self-esteem $(r=-0.3 ; p=0.01)$.

\section{CONCLUSION}

The low practice of physical activities by patients with JIA seems to directly influence both, their body composition and their self-esteem. These patients should be encouraged to increase physical activity from an early age by a multiprofessional healthcare team to seek improvement their quality of life.

\section{KEYWORDS}

Juvenile idiopathic arthritis, International physical activity question, Quality of life. 